\title{
Articulaciones de la violencia contra la mujer en el marco de las narrativas del conflicto armado colombiano*
}

\section{Articulations of Violence Against Women in the Colombian Armed Conflict Narratives Frame}

\begin{abstract}
Resumen
Algunas de las narrativas recientes del conflicto colombiano han puesto el énfasis de la representación en la diversidad de repertorios de violencia que se inscriben, en el marco del conflicto armado, sobre los cuerpos de las mujeres. En este sentido, estas representaciones articulan un régimen de visibilidad, al problematizar los modos en que estas violencias se encuentran estructuradas y legitimadas en el marco social. En este artículo se analizan las formas específicas en que la violencia opera sobre los cuerpos femeninos en las novelas: Era mucho el miedo (2016) de Gloria Inés Peláez, La fruta del borrachero (2018) de Ingrid Rojas Contreras y La sembradora de cuerpos (2019) de Philip Potdevin.
\end{abstract}

Palabras claves

Mujeres, Violencia de género, Narrativas del conflicto, Literatura colombiana.

\begin{abstract}
Some recent narratives about the armed conflict in Colombia have stressed the representation on the diversity of violence repertoires inscribed in the armed conflict frame upon women's bodies. In this sense, these representations articulate a regime of visibility, as they

* El presente análisis se inscribe en el marco de mi tesis doctoral: "Violencia y capitalismo: regímenes de la representación y nuevas modulaciones de la violencia en la literatura colombiana reciente", asesorada por el Dr. Danilo Santos y el Dr. Fernando Blanco. Esta investigación se encuentra financiada por la Agencia Nacional de investigación y Desarrollo de Chile (ANID), $\mathrm{N}^{\circ} 21180972$.
\end{abstract}


CATEDRAL TOMADA: Revista de crítica literaria latinoamericana / Journal of Latin American Literary Criticism Articulaciones de la violencia contra la mujer en el marco de las narrativas del conflicto armado colombiano

problematize the ways in which the different cases of violence are structured and legitimized in the social frame. This paper analyzes the specific ways that the violence operates upon feminine bodies in the novels: Era mucho el miedo (2016) by Gloria Inés Peláez, La fruta del borrachero (2018) by Ingrid Rojas Contreras and La sembradora de cuerpos (2019) by Philip Potdevin.

Keywords Women, Gender violence, Conflict narratives, Colombian literature.

\section{La mujer en el conflicto}

El largo conflicto armado que ha vivido Colombia desde hace más de 60 años ha afectado de manera diferenciada a distintos grupos sociales de acuerdo con condiciones etarias, étnicas, económicas y de género. A su vez, la interseccionalidad de estos factores ha determinado no solo los grados de violencia que recaen sobre los cuerpos, sino también las intensidades con las que la violencia se inscribe en el territorio, lo que ha tenido como resultado la vulneración de ciertas subjetividades y comunidades de manera más sistemática.

En este contexto, las mujeres ${ }^{1}$ han sido un grupo poblacional ampliamente violentado a través de múltiples repertorios de violencia, los cuales han recaído en mayores grados sobre mujeres indígenas o afrocolombianas y sobre niñas y adolescentes $^{2}$. Este reconocimiento de la violencia que se ha ejercido sobre el cuerpo de la mujer en el marco del conflicto armado colombiano no pretende desconocer el rol activo que han tenido muchas de ellas en él. Sin embargo, lo que

${ }^{1}$ El concepto mujeres no se entiende aquí en términos identitarios esencialistas, sino en un sentido performativo como "un significante parcial o provisional" (Luongo 168), siempre desplazado, que, "como un sitio permanente de oposición o como un sitio de lucha angustiosa" (Butler 311) puede agrupar diversidad de subjetividades. En el caso específico del presente análisis, de acuerdo con el corpus novelar analizado, el significante mujeres se corresponde con las sujetos cuya performatividad "exhibe los significantes femeninos" (Segato 23).

2 Al respecto señala el informe: La guerra inscrita en el cuerpo, Informe nacional de violencia sexual en el conflicto armado, que los territorios de las comunidades indígenas y afrocolombianas han sido los espacios que históricamente han sido más violentados. Por esto "las mujeres indígenas y las mujeres afrocolombianas han insistido en afirmar que la violencia sexual sobre sus cuerpos constituye una práctica de dominación que ha persistido desde la colonización y que ha hecho parte de una estrategia sistemática de ejercicio de poder sobre ellas y sus territorios. Sobre ellas se han ejercido prácticas de dominación que se relacionan con la raza, pero, además, con los significados otorgados a las niñas, niños y adolescentes, cuyo objetivo es doblegarlas y amedrentarlas" (196). 
aquí interesa particularmente, es analizar los modos en que determinados tipos de violencias se inscriben de manera diferenciada en los cuerpos de las mujeres por su condición de género en el marco de este conflicto armado capitalista-patriarcal.

La amplitud y complejidad del conflicto armado no permite hablar en términos generales de una violencia contra la mujer, pues los repertorios que la estructuran son diversos y variados y responden a diferentes factores, como las dinámicas particulares de cada territorio, las lógicas de guerra de los actores armados responsables en cada caso y, además, de los procesos de subjetivación particulares de los integrantes de estos grupos.

Algunos de los informes enfocados en el problema de género, publicados por la Comisión Nacional de Reparación y Reconciliación-Grupo de Memoria Histórica (CNRR-GMH), luego convertido en Centro Nacional de Memoria Histórica (CNMH), dan cuenta de la especificidad de las prácticas violentas ejercidas contra las mujeres. En estos informes se explicitan los modos en que estas violencias, en cada caso, estaban determinadas por lo que implicaba ser mujer en el marco de cada una de las comunidades violentadas y los procesos de subjetivación que las estructuraban como tales en dichos contextos sociales específicos. Uno de estos informes, La masacre de Bahía Portete. Mujeres wayúu en la mira (CNRR-GMH, 2010), expone la manera en que la violencia en contra de las mujeres wayuu respondió al rol que estas cumplían en sus comunidades:

Comprender el papel de la mujer wayúu implicó identificar la dimensión de género del ataque paramilitar y determinar el mensaje que este pretendía mandar a la comunidad indígena. En la medida en que las mujeres wayúu tenían posiciones de liderazgo, participaban en el lucrativo negocio del contrabando, por medio de su actividad de comerciantes, y constituían el vínculo con la población no indígena, el seleccionarlas como víctimas, garantizaba asestar un duro golpe que propiciara el desplazamiento de sus miembros. (CNMH, Género y memoria 59) 


\section{La violencia sexual}

Específicamente, la violencia sexual ha sido la práctica que de manera más sistemática y generalizada se ha ejercido contra las mujeres en el marco del conflicto colombiano, por parte de todos los actores armados involucrados en él, estatales y no estatales. En este contexto "los cuerpos de las mujeres han sido utilizados [...] para lograr objetivos militares y como botín de guerra" (Sisma, Colombia 1). De estas prácticas dan cuenta algunos datos del CNMH que señalan que "entre 1958 y 2017 un total de 15.076 personas fueron víctimas de violencia sexual; [de las cuales] el 91,6\% eran mujeres” (CNMH, ¿Qué papel...? párr. 1).

Las prácticas de violencia sexual son amplias, al igual que la diversidad de subjetividades sobre las que estas han recaído, pues los procesos de victimización sexual no se han inscrito solo en el cuerpo de las mujeres sino también en muchas otras corporalidades e identidades sexuales diversas. En cuanto a la vastedad y heterogeneidad de estas prácticas la Ley 1448 de junio de 2011 reconoce una extensa variedad de delitos en contra de la "libertad e integridad sexual tales como: aborto forzado, anticoncepción forzada, explotación forzada, trata de personas, abuso sexual, embarazo forzado, planificación forzada, pornografía infantil, acceso carnal violento, esclavitud sexual, entre otros, que constituyen una grave violación a los derechos humanos" (Atención y reparación, párr. 4).

En este complejo repertorio, una de las prácticas de violencia sexual más recurrente y sistemática ha sido la de la violación. Esta modulación de la violencia se ha dado de manera transversal en gran parte de los territorios afectados por el conflicto. Al respecto, "una encuesta llevada a cabo por las organizaciones de mujeres que abarca un período de nueve años (2000-2009) estima que 12.809 mujeres fueron víctimas de violación relacionada al conflicto" (Sisma, Colombia $1)$.

En el informe Mujeres y guerra. Victimas y resistentes en el Caribe colombiano (2011), el CNMH distingue entre dos modalidades de esta violencia: la violación sexual estratégica y la violación sexual oportunista. La primera, hace referencia a aquellos casos de violación que se cometen como una táctica de guerra 
que busca reafirmar procesos de dominación de los territorios a través del sometimiento de los cuerpos femeninos. La segunda, se refiere a aquellos casos en los que la violación es cometida como un hecho "individual", aislado del accionar organizacional de los grupos armados.

Este tipo de aproximaciones al problema de la violencia sexual constituyen un avance parcial para su entendimiento, sin embargo, deben ser complementados, para que no terminen simplificando el problema al perder de vista otros factores que lo condicionan como fenómeno social. En este caso particular sería necesario considerar que las prácticas que configuran la violencia sexual se articulan de manera compleja en los procesos de subjetivación de los sujetos victimarios, procesos que no pueden ser reducidos a la lógica de la confrontación bélica ${ }^{3}$ sino que deben ser entendidos de manera transversal en relación con entramados culturales, políticos, económicos y sociales. Como lo señala el informe "Colombia: Mujeres, Violencia Sexual en el Conflicto y el Proceso de Paz", para entender el impacto de la violencia sexual en el contexto del conflicto armado es necesario "comprender el contexto social y cultural de este crimen. Además de los sistemas patriarcales basados en la dominación y la discriminación de género, existen otros factores como la marginación social, política y económica que deben ser tenidos en cuenta" (Sisma, Colombia 1).

En este sentido debe reconocerse la magnitud y complejidad de este problema, en el que es necesario un trabajo constante y crítico y un diálogo abierto que permita escuchar y analizar las condiciones y situaciones tanto de las víctimas desde un lugar central, como también de los victimarios. De este modo sería posible entender las lógicas de estas violencias y establecer las responsabilidades fácticas y sistémicas que las estructuran, ofreciendo así procesos de reparación y justicia para las víctimas, que acaben con las dinámicas de la impunidad y el silenciamiento que han invisibilizado y encubierto esta realidad por tantos años.

3 Para una crítica a esta categorización véase el capítulo "Contribuciones del CNMH a la comprensión de género del conflicto" del informe: Género y memoria histórica Balance de la contribución del CNMH al esclarecimiento histórico (2018). 
CATEDRAL TomAdA: Revista de crítica literaria latinoamericana / Journal of Latin American Literary Criticism Articulaciones de la violencia contra la mujer en el marco de las narrativas del conflicto armado colombiano

\section{Representaciones literarias de y sobre la mujer}

Las narrativas literarias sobre el conflicto armado colombiano han puesto de manifiesto de diferentes formas este preocupante estado de cosas, explicitando los amplios repertorios de violencia que, de manera cotidiana, recaen sobre el cuerpo de la mujer. Así, existen diversos ejemplos recientes que desde la representación crítica de estas violencias complejizan los modos de entender el problema, enfatizando en las formas en que este impacta las distintas etapas de la vida de la mujer y los imaginarios asociados a cada una de ellas: desde la infancia (Rojas 2018, Tarquino 2018, Esquivel 2017, Vélez 2015), pasando por la adolescencia-juventud (Rojas 2018, Peláez 2016, Potdevin 2019) y la adultez (Escobar 2019, Ospina 2019, Ferreira 2014).

El presente análisis se enfoca, específicamente, en aquellas narrativas que representan lo que aquí se denomina régimen de la infancia y la adolescencia. En este régimen, inscrito en un espacio intersticial subjetivo que se instala entre estos dos estadios, el de infancia y la adolescencia, emergen unas subjetividades desplazadas que fluyen entre ambos espacios. Estas sujetos, se sobreponen a la violencia que se inscribe en sus cuerpos y territorios y logran afirmar, unas con mayor efectividad que otras, diferentes modos de relación social que tienden a la reconfiguración del lazo social, fracturado no solo por las lógicas del conflicto sino también por las prácticas económicas intensivas del capitalismo contemporáneo.

En este sentido, se analizarán algunos de los personajes femeninos presentes en las novelas: La fruta del borrachero (2018) de Ingrid Rojas Contreras, La sembradora de cuerpos (2019) de Philip Potdevin y Era mucho el miedo (2016) de Gloria Inés Peláez. El énfasis de este análisis radicará en los modos en que la violencia se imprime en el cuerpo de las mujeres y en la manera en que estas logran superar, o no, estas prácticas de violencia a través de la afirmación de otros regímenes de los afectos que no reproducen la violencia y que tienden a la restauración del tejido social. 


\section{Tres modulaciones de la violencia}

Las novelas que constituyen este análisis coinciden en representar subjetividades femeninas que oscilan entre la infancia y la adolescencia, aunque las condiciones del espacio social y familiar que habitan les demande un agenciamiento adulto. En La sembradora de cuerpos, la personaje principal es Frida, Sigfrida, una niña de 12 años que vive junto a su madre y dos hermanas en un pueblo llamado Las Brisas de donde fueron desplazadas forzadamente, junto a toda la comunidad, por un grupo paramilitar que operaba en la zona y que disputaba el territorio con grupos guerrilleros.

Adelita, es la protagonista de Era mucho el miedo. Ella vivía junto a su esposo, un policía, en el pueblo de Venadillo, hasta que este fue asesinado en una toma guerrillera a la estación de policía del pueblo. Adelita, menor de edad y embarazada se ve obligada a regresar a la casa de su madre, a Lérida, donde habían vivido luego de haber sobrevivido a la avalancha de Armero que arrasó la ciudad en 1985. Por su parte, La fruta del borrachero representa a una familia de clase media alta bogotana, que contrata como empleada a Petrona, una adolescente de 13 años que vive en Los Cerros, a las afueras de la ciudad. Ella había llegado a este barrio junto a su familia luego de ser desplazada por grupos paramilitares que quemaron la casa de su familia en Boyacá y desaparecieron a su padre y a dos de sus hermanos.

En cada una de estas narrativas la dinámica social está fuertemente determinada por el conflicto armado colombiano y la diversidad de agentes violentos que lo configuran, los cuales, en la larga historia de la violencia del país, han terminado por ser indistinguibles entre sí. Estos grupos armados estatales y no estatales, con su accionar contra la población civil y sus economías ilegales sostenidas en la violencia, han devenido en organizaciones criminales, para las cuales la violencia se ha convertido en un fin en sí misma. En este sentido, puede leerse el hecho de que justamente los dos líderes de los grupos armados que ejercen la violencia en La sembradora de cuerpos, Anastasio y Josefo Farfán sean hermanos gemelos, el primero comandante de la guerrilla, el segundo de los 
paramilitares. En ellos se cristaliza no solo esa indistinción alcanzada por la guerra sino también el colapso de instituciones tradicionales como la familia.

Específicamente, en los contextos precarios que se representan, la familia opera como una institución que demanda de los sujetos una responsabilización económica $\mathrm{y}$, en algunos casos, un empoderamiento violento. En este último sentido se inscribe el mandato masculino a ejercer la violencia como mecanismo de resarcimiento frente a la misma, el llamado a cobrar venganza. Se puede recordar aquí la escena de la película colombiana de Víctor Gaviria "La vendedora de rosas" (1998), en la que El Zarco le dice a su hermano: "usted tiene que responder por mí, y si alguien me mata usted va a crecer, y cuando usted crezca usted vio quien me mató, porque usted me debe cuidar mi espalda" (1:30'-1:31'). Esta es la herencia masculina, Hamletiana, que instaura el mandato de agenciarse violentamente para exigir justicia; herencia a la que se opone abiertamente el régimen no masculino que se puede denominar Antigónico ${ }^{4}$, el cual representan algunas de las personajes de estas novelas. Este régimen demanda y exige justicia sin reproducir la violencia. Un ejemplo del primer sentido de la demanda de justicia es el de Fernandito, hermano de Petrona, quien después de la muerte de otro de sus hermanos a la edad de doce años a manos del Ejército o de los paramilitares, habla de este modo con su hermana:

Fernandito me dice que es el hombre de la casa como lo fue Ramoncito alguna vez. Trato de pensar qué palabras decir. Confía en mí. Puedo cuidarte. Fernandito me dice que es fuerte y que matará. Doce años de edad, se pasa el tiempo recogiendo palos y piedras, jugando con ellas como

${ }^{4}$ Se retoma aquí la imagen de Antígona en un sentido ampliado, más allá del trabajado de su demanda de justicia que superpone lo filial sobre lo estatal autoritario (Llanos 184). Aquí su figura es evocada en un sentido postinstitucional, poniendo el énfasis en su negación a ejercer la violencia, implicada esta en la demanda de odiar y por tanto negar sepultura a uno de sus hermanos. De este modo, su negación se direcciona hacia la reproducción de otro régimen de los afectos, explícita cuando Antígona habla a Creonte diciendo: "Mi persona no está hecha para compartir el odio, sino el amor" (Sófocles 156). 
si fueran AK-47, machetes y granadas. Dice que se hará soldado, policía, guerrillero, paramilitar. Para él no hay diferencia. (Rojas 211)

Estas demandas en contextos precarios y violentos impulsan a los sujetos, masculinos con mayor frecuencia, a procesos de necroempoderamiento ${ }^{5}$, que reproducen largamente el ciclo de la violencia. Estos procesos pueden verse ampliamente representados en las narrativas sicariales, en las que la figura de la madre necesitada, carente, símbolo de lo familiar y lo sagrado, aunada a unas demandas de consumo, llevan a los sujetos a ejercer la violencia como modo de existencia y figuración social.

Por su parte, en las narrativas que constituyen este análisis, este régimen masculino de la reproducción de la violencia es desplazado por algunos personajes femeninos. De esta afirmación de una no violencia como legado da cuenta Adelita, quien luego de reencontrarse con un guerrillero que había participado en la toma en la que murió su pareja, y verlo perseguido por la policía, lo ayuda, hasta que desaparece, "imaginé a David muerto en su propio operativo, con los ojos abiertos, buscando su dinero. Y no me alegré sino que sentí pena: no quería una venganza por lo de Venadillo" (Peláez 242). Asimismo, Chula siente una vinculación afectiva y gran preocupación por Petrona, a pesar de que esta hubiera participado en un intento de secuestro llevado a cabo contra ella. Así, mientras su padre está secuestrado y no tiene ninguna razón de Petrona, Chula los iguala a ambos en su preocupación, sintiéndose incluso culpable por haber dejado a Petrona a su suerte. Estos casos muestran la articulación de ese régimen afectivo Antigónico, que va más allá de la simple reproducción de la violencia al cortarla de plano y al afirmar la posibilidad del restablecimiento de un lazo social, incluso con aquellos que ejercieron la violencia directa e indirecta contra ellas.

5 En su texto Capitalismo Gore, la investigadora mexicana Sayak Valencia define el necroempoderamiento como: "los procesos que transforman contextos y/o situaciones de vulnerabilidad y/o subalternidad en posibilidad de acción y autopoder, pero que los reconfiguran desde prácticas distópicas y autoafirmación perversa lograda por medio de prácticas violentas" (205-206) 


\section{Repertorios de violencias contra la mujer}

Las tres personajes que interesan en este análisis, Frida, Adelita y Petrona, son personajes adolescentes cuya subjetividad, como se mencionó antes, oscila entre los estadios de la infancia y la adultez de manera abrupta por los contextos de violencia y las condiciones de precariedad en los que se desarrollan sus vidas. Los impactos psicológicos y físicos de la violencia estructuran unos procesos de subjetivación específicos. Petrona no parecía de trece años, tenía “ojos de vieja amargada” (Rojas 27), “estaba atrapada en algún lugar entre mujer y niña” (85), su performance, que es descrito por Chula, es agotado, estático, pétreo, nunca sonríe, habla poco. Frida ha hecho "demasiado rápido el tránsito de la inocencia a la experiencia. Hoy sus ojos carbón [...] son los de una mujer curtida. Aquí, ahora, es posible envejecer años en un día o dos; a veces, en un par de horas" (Potdevin 1112). La sistematicidad de los procesos de violencia estructura unas subjetividades que devienen anestésicas ante la violencia, las cuales están atravesadas por un deterioro físico y psicológico producto de los excesos de esta. Así, la violencia articula de un modo determinado sus corporalidades, no solo desde las huellas que les imprime sino también desde la forma en que disciplina sus cuerpos, en este caso, femeninos adolescentes.

La representación de estas sujetos, cuyas edades varían entre los 12 y 16 años de edad, resulta relevante en el contexto colombiano, ya que este rango poblacional ha sido el más afectado por la violencia sexual. Según el Boletín número 17 de la Corporación Sisma Mujer, en cuanto a este tipo de violencia contra niñas y adolescentes, de acuerdo con datos del Instituto Nacional de Medicina Legal y Ciencias Forenses, de los "22.304 casos registrados [...] en 2018, 19.323 corresponden a niñas y adolescentes, es decir, el 86,6\% del total de mujeres agredidas. Dentro de este grupo, las niñas que tienen entre 10 y 14 años son las más afectadas: 41,9\%" (Sisma, Reconocer 9).

En los contextos representados en las novelas, la violencia pasa y se inscribe en los cuerpos de las mujeres de un modo particular a través de determinadas 
prácticas y repertorios específicos, los cuales no son exclusivos de los contextos de guerra, pero sí los modos en que estos operan como significantes con una determinada efectividad simbólica. En este sentido, la violencia física y psicológica que recae sobre los cuerpos femeninos, y sobre otros cuerpos que son feminizados, se encuentra determinada por unas estructuras de género jerarquizadas, en las que la dominación es ejercida y detentada por una masculinidad hegemónica patriarcal. Como señala Pierre Bourdieu, en nuestras sociedades occidentales:

La dominación masculina tiene todas las condiciones para su pleno ejercicio. La preeminencia universalmente reconocida a los hombres se afirma en la objetividad de las estructuras sociales y de las actividades productivas y reproductivas, y se basa en una división sexual del trabajo de producción y de reproducción biológico y social que confiere al hombre la mejor parte, así como en los esquemas inmanentes a todos los hábitos.

Esta dominación masculina, como señala Bourdieu, se inscribe y reproduce en las estructuras sociales, de modo que sus manifestaciones fenoménicas en general están tan profundamente normalizadas y sedimentadas en los procesos de socialización y racionalización ${ }^{6}$, que no son perceptibles y, por tanto, en muchos contextos no pueden ser problematizadas. En este sentido, las estructuras de género que son estructuras de poder (Segato 2003), se encuentran diseminadas en multiplicidad de prácticas y comportamientos, que tienden al mantenimiento de este status quo. La dominación simbólica se produce y reproduce mediante "los esquemas de percepción, de apreciación y de acción que constituyen los hábitos y

${ }^{6} \mathrm{Al}$ respecto afirma Jessica Benjamin que: "Resulta difícil captar el hecho de que el centro de la dominación masculina no se encuentra en las expresiones directas de la violencia personal (por difundidas que estén), sino en la racionalidad social que puede o no ser defendida por los hombres. La dominación masculina, como dijo Weber de la racionalización, opera a través de la hegemonía de la organización impersonal: a través de reglas formales que se refieren a la interacción hipotética de individuos autónomos; de un conocimiento instrumental basado en el control por el sujeto del mundo de objetos; de la acumulación de utilidades, que no se inclina ante la necesidad ni la tradición. Es esta impersonalidad proteica lo que la hace tan elusiva" (264-65). 
CATEDRAL TomAda: Revista de crítica literaria latinoamericana / Journal of Latin American Literary Criticism Articulaciones de la violencia contra la mujer en el marco de las narrativas del conflicto armado colombiano

que sustentan, antes que las decisiones de la conciencia y de los controles de la voluntad, una relación de conocimiento profundamente oscura para ella misma" (Bourdieu 55).

Las relaciones de género, que no se limitan a las relaciones entre lo masculino-femenino, son siempre un territorio en disputa, tensado de manera constante. En esta línea, la masculinidad patriarcal, pese a estar sedimentada en estructuras sociales, requiere de una afirmación constante en el marco de las interacciones sociales, como señala Rita Segato, la masculinidad es un estatus que se adquiere, se conquista, por eso siempre "existe el riesgo constante de perderlo y por lo tanto, es preciso asegurarlo y restaurarlo diariamente. Si el lenguaje de la femineidad es un lenguaje performativo, dramático, el de la masculinidad es un lenguaje violento de conquista y preservación activa de un valor" (Estructuras 38).

En este sentido, la multiplicidad de violencias ejercidas contra las mujeres opera como una afirmación de autolegitimación del poder masculino. Las narrativas analizadas en este texto exponen, precisamente, esa diversidad de violencias que operan contra la mujer de manera explícita e implícita en diferentes planos sociales, políticos y culturales, de acuerdo con unas condiciones específicas de los territorios y con las dinámicas con las que el conflicto armado se inscribe en él.

\section{De regímenes pedofílicos}

"Yo creo que síquería a la muchacha aunque ella era muy joven para él, pero hay hombres a quienes les gustan así, niñitas dizque para criarlas y quitarles las mañas, eso dicen". (Peláez 24)

En Era mucho el miedo se expone una de las estructuras más preocupantes que se instauran violentamente en el cuerpo de la mujer, esta es la del régimen pedofílico, que con una fuerte complicidad social consume y configura de unas formas determinadas los cuerpos de la niñas, adolescentes y mujeres adultas. En 
esta representación, Peláez complejiza este problema al mostrar cómo este régimen, que sexualiza la infancia e infantiliza sexualmente la adolescencia y la adultez, articula las relaciones de pareja, familiares y sociales en general.

Adelita es una joven adolescente, su esposo Nacho es veintiún años mayor que ella. Las prácticas que configuran el universo conyugal están fuertemente marcadas por la voluntad masculina que demanda de Adelita un comportamiento infantil. En este sentido la relación se constituye en el marco de una lógica paternal: él la lleva al colegio de la mano y la deja en la entrada con un beso en la frente (Peláez 60), la sienta en sus piernas y la peina (49), le da dulces y peluches al regresar de sus viajes y confirmar que se ha portado "bien" (156). Igualmente, la sexualidad de la pareja está cargada por estos roles, así mientras Nacho sienta a Adelita en sus piernas para peinarla, se balancea. Estos movimientos son codificados por ella a modo de juego infantil, que es justamente lo que él disfruta, dice Adelita: "reía porque me parecía que yo era el caballo de Nacho y él era mi jinete. ¡Upa, caballo, que va pa' Belén, a ver a la Virgen y al niño también!” (49). Asimismo, en esta dinámica es ilustrador el primer encuentro sexual entre ellos:

Adelita, ¿le darás un beso en la boca a tu papito, ahora? ¿Dejarás que tu papi te sople el ombliguito? [...] Con un brazo, Nacho me rodeó y metió la mano libre debajo de mi falda. Sentí sus dedos subir tanteando nerviosos por mis muslos, los abrió y los metió entre mi sexo. Un corrientazo que venía de algún lugar de mi cuerpo me echó hacia atrás pero el brazo firme de Nacho me retuvo; sus dedos me acariciaban y me hacían daño pero no podía moverme. Intenté romper el abrazo pero lo que hice fue aferrarme a su pecho, hasta que sentí la boca de Nacho y su lengua penetrando en mi boca, y entonces me rendí y dejé que hiciera lo que deseaba. (62-63)

En estas escenas y diálogos, con una fuerte carga incestuosa, es evidente la alusión al diálogo pedófilo del violador, que articula un discurso que vincula los imaginarios y prácticas de la infancia como modo de acceder sexualmente a una 
menor. Del mismo modo, en esta última escena resulta explícita la violencia sexual con la que se desarrolla el acto, el hombre se impone físicamente y acalla de manera violenta la duda y el malestar corporal que el acto produce en ella. Adelita no tiene otra opción que someterse y satisfacer el deseo de él, que es el deseo de la dominación misma como afirmación del poder masculino, mientras que el suyo propio, no puede más que ser aplazado, “[Él] se levantó y me dejó en la cama. Y mientras Nacho se arreglaba, yo suspiraba porque aún no se me había pasado la fiebre que me había subido cuando él me metió la mano" (64).

Este régimen relacional, con una noción de infancia, hace parte de las estructuras sociales patriarcales, las cuales están sostenidas en muchas complicidades directas e indirectas de las esferas familiares, institucionales y sociales en general. La madre de Adelita contribuye al disciplinamiento de su cuerpo en función de este régimen pedofílico; así ella le teje la ropa a la joven de modo que responda a la necesidad del deseo masculino, "observé mis piernas cubiertas apenas por la tela vaporosa de la falda, una de las prendas que mi madre me arregló para que yo me vistiera como le gustaba a Nacho, rebajándole una talla a mis medidas" (70). Aquí se evidencia cómo, en su ejercicio del poder, el hombre determina la corporalidad del otro. Adelita está obligada a verse y a actuar de un modo infantil, de ahí que tema que Nacho la haya dejado de querer porque con su embarazo, ella había dejado de ser una niña para él (95). En este mismo sentido, destaca el comentario de Olivia, la otra infantil amante de Nacho, quien manifiesta que él la estaba dejando de querer porque "le molestaba que fuera una señorita y no una niñita, como la conoció" (213). El dominio masculino demanda de la mujer una infantilidad eterna que anula cualquier posibilidad de empoderamiento, una infantilidad a la medida de sus deseos: incompleta, inocente, carente y vulnerable, que legitime su autoridad, dominación y poder como adulto-hombre.

En La sembradora de cuerpos, esta complicidad con la violencia masculina que opera en desmedro de lo femenino la encarna Clara, la tía del paramilitar Josefo Farfán. Esta mujer no emite juicio alguno frente al hecho de que su sobrino le “encargue" el cuidado, forzado, de Frida, una niña de tan solo 12 años, de la que él 
dice que es su mujer. Ella accede a tenerla en su casa como una presa de su sobrino. Este caso muestra una vez más cómo la violencia patriarcal se sostiene no solo en la acción directa sobre las subjetividades violentadas, sino también en otra serie de violencias ejercidas por otros u otras sujetos cómplices y, en algunos casos, por las mismas sujetos violentadas, que contribuyen en la legitimación y reproducción de este régimen estructural, ya que "el poder simbólico no puede ejercerse sin la contribución de los que lo soportan porque lo construyen como tal" (Bourdieu 56).

Esta relación contradictoria de reproducción y complicidad con un régimen que violenta la propia subjetividad y al propio género se debe a que estas prácticas responden a profundos procesos de subjetivación, que inscriben en los sujetos unos modos de relacionarse socialmente, los cuales se articulan de acuerdo con unas lógicas hegemónicas del poder heteropatriarcal. En este orden, resulta complejo a los sujetos subalternizados oponer resistencias a las lógicas que los oprimen, como señala Bourdieu "los dominados aplican a las relaciones de dominación unas categorías construidas desde el punto de vista de los dominadores, haciéndolas aparecer de ese modo como naturales" (50). Así, estos modos de relación jerarquizados aparecen normalizados en el orden social mismo y, por tanto, son incuestionables, no modificables.

Estas estructuras de dominación entonces se soportan y se reproducen a través de la labor de agentes singulares y de agentes institucionales: Familia, Iglesia, Escuela, Estado (Bourdieu 50). En línea con esto, a propósito de la complicidad de la institución Iglesia con este régimen específicamente pedofílico, se puede interpretar el episodio relatado por Adelita, cuando refiere que a sus once años tenía que confesarse obligatoriamente una vez al mes con el cura de la escuela. Allí llegaban las estudiantes asustadas y temerosas a postrarse ante aquel hombre:

[P]arecía tan interesado que le contáramos en detalle cómo eran nuestros malos pensamientos y con quién, qué cosas hacíamos cuando le susurrábamos turbadas que nos veíamos con al noviecito para besarnos en la boca, [...]. Y él seguía preguntando curioso por si se había olvidado 
algún detalle, o qué hacíamos mientras pensábamos en esas cosas [...] me llegaba su voz ronca inquiriendo que le contara mis fantasías pero despacio para que él pudiera curarme del pecado, y yo pensaba que debía hacerlo porque sin duda él era un hombre santo. Y le decía para alegrarlo que imaginaba estar besándome con un hombre grande. ¿Qué tan grande? volvía a preguntar y sus ojos brillaban, lo veía por los roticos del mimbre de la rejilla. Como mi papá, le decía. Veía que el cura se removía en el asiento, insistía que continuara con la confesión y me pedía que le contara como lo haría y con detalles. No se preocupe, padre, porque mi papá está muerto, le respondía. El cura suspiraba y era como si se desinflara. Parecía que se desengañaba de mi pecado. Me daba la penitencia y su bendición con desgano. (Peláez 36-37)

El cura, representante de la institución religiosa, unas de las instituciones que más relevancia y autoridad ha tenido por décadas en los entornos rurales colombianos, encarna aquí como figura institucional y masculina, la legitimación de un orden jerárquico patriarcal. Este orden ostenta de manera evidente la dominación masculina, como señala Francesca Gargallo, “a nivel práctico, el sacerdote del catolicismo es un hombre, y a nivel simbólico, su divinidad se representa como una figura masculina acompañada de una figura femenina de menor rango, una mujer misericordiosa y madre, pero asexuada y virgen" (73).

Este régimen moral hipócrita católico, en la figura de este sacerdote, instrumentaliza la culpa, no solo en función de su deseo individual, que es a su vez colectivo, sino también como afirmación de ese orden patriarcal católico. Así, la escena evidencia dos registros, por una parte, el de la satisfacción del propio deseo pedófilo, a partir de la escucha de los deseos otros de esas subjetividades infantiles pasados por la palestra del confesionario; y, por otra parte, el registro condenatorio de las infantes por la manifestación de esos deseos pecaminosos a través de la penitencia. En este último término, al condenar el deseo o pulsión sexual femenino, expresado aquí no sin ironía por Adelita, lo que se legitima es la exclusividad y 
pertenencia de este registro a lo masculino. En el paradigma de la moral católica, el deseo y la sexualidad femenina debe ser negada y castrada, para que emerja sin ambigüedad su rol social como madre abnegada y protectora del hogar.

El caso más crítico, que redondea la sistematicidad de este denominado régimen pedofílico, es el caso de la "Casa de las Muñecas", mencionado en Era mucho el miedo. Este era un lugar en el que se explotaban sexualmente a niñas y niños. Esta casa que estaba ubicada en la ciudad de Armero, antes de que la avalancha la arrasara, era muy famosa, a ella venían hombres de otras ciudades cercanas. Al respecto cuenta el rezandero que visitó la casa de Adelita y su madre:

[N]o era una casa de citas cualquiera, no señorita, quien viera lo que allí sucedía sólo observaba a unos señores grandes jugando con esas niñitas. Las sentaban en las rodillas y las aupaban como montándolas en caballito. Y eso las mujeres las vestían con ropas chiquitas que parecieran más niñas todavía, y ellos las peinaban y les ponían moños, así con el pelo dividido en dos colitas. (Peláez 105)

El hombre continúa relatando que eso era lo que se podía ver en el salón principal, más atrás había unas habitaciones, donde luego de beber y "jugar” con las niñas, estas eran conducidas por los hombres. En este punto, el relato expone uno de los vejámenes más graves de la violencia sexual que sufren niñas y niños, la explotación sexual infantil. La narración da cuenta del modo en que ciertos cuerpos vulnerables son violentados de manera sistemática al ser capitalizados y explotados bajo las lógicas del capital. Estos cuerpos infantiles objetualizados son ofrecidos para el consumo perverso de la masculinidad pedofílica ampliamente descrita en la novela. Asimismo, el modo en que es narrado este problema en la novela expone, una vez más, la connivencia social que encubre este tipo de delitos sexuales contra la infancia. La madre de Adelita, escucha con recelo lo que el hombre cuenta y en cuanto tiene oportunidad lo calla para que no siga hablando, pues esto es algo que simplemente debe quedarse en el pasado. Del mismo modo, 
CATEDRAL TomAda: Revista de crítica literaria latinoamericana / Journal of Latin American Literary Criticism Articulaciones de la violencia contra la mujer en el marco de las narrativas del conflicto armado colombiano

se sobreentiende en el relato que Nacho, el esposo de Adelita, quien era policía en la Estación de Armero, frecuentaba este lugar. Aquí, de nuevo, como en el caso del cura, la figura de un sujeto particular encarna la política sistemática del encubrimiento y la complicidad institucional en la violencia sexual ejercida contra las infancias.

\section{La lógica de apropiación del cuerpo femenino}

Otra de las violencias que opera en el régimen patriarcal en contra del cuerpo de la mujer está constituida por la lógica de la apropiación de sus cuerpos por parte de aquellos hombres detentadores de una masculinidad hegemónica. Esta lógica de pertenencia que, supedita las corporalidades femeninas a las masculinas, se manifiesta de modos diferentes en las tres novelas. Sin embargo, el énfasis de este análisis se centrará en las problematizaciones que se dan en este sentido en Era mucho el miedo, a través de la relación de Adelita con su esposo Nacho y en La sembradora de cuerpos en la vinculación mediada por la violencia sexual que establece Josefo Farfán con Frida.

La pertenencia de la mujer se reafirma de manera constante a través de diferentes repertorios de violencia, que abarcan dimensiones físicas y psicológicas y que, a su vez, es condicionada por unas lógicas de dependencia emocionales y económicas de la mujer frente a la figura masculina dominadora, lo cual responde a unas estructuras de poder inscritas en roles sociales establecidos. Todas estas manifestaciones de la dominación masculina se encuentran representadas en la relación de Adelita con Nacho. Ella, de manera constante, evidencia tanto las violencias que recaen sobre ella, como las que se ciernen de forma latente sobre su cuerpo. Así, por una parte, la joven se siente constantemente amenazada por él: "creí que me lastimaría" (9), "yo miré que no me vieran hablando con un hombre. Imaginaba a Nacho tirándome del pelo, furioso por encontrarme con un extraño y me asusté” (16). Por otra parte, él también despliega físicamente esa violencia enunciada como latencia: "los celos que lo cegaban y lo hacían arrojarme contra las 
paredes" (18), cuando él la descubre en una situación comprometedora con el capitán Rojas, ella relata:

Tuve mucho miedo de quedarme a solas con Nacho [...]. Salimos de la Estación y caminamos una cuadra hasta la casa donde teníamos la habitación, la última que yo habité con Nacho antes del ataque. Entramos y dejé la puerta abierta de puro susto de encerrarme: él con una patada la cerró. ¿Qué te estaba haciendo el capitán?, gritó. ¡Nada!, le dije, ¡sólo me lamió una oreja! Su ira creció y me empujó contra la pared: ¡Mentirosa! Apenas tuve tiempo de poner las manos para no chocar muy duro. No supe qué decirle para apaciguarlo. (129)

La violencia física y psicológica inscrita sobre la subjetividad femenina es una ratificación simbólica de la pertenencia. En los relatos, este régimen contractual de posesión se establece a partir del acceso sexual al cuerpo de la mujer, sea este consensuado o no. Después del primer encuentro sexual antes descrito, entre Nacho y Adelita, ella misma es quien afirma para sí misma el vínculo contractual que allí quedó establecido, manifiesta: "de esa manera sentí que ya era la mujer de Nacho y que ya no podría querer a ninguno otro" (63). Por su parte, él proclama oficialmente su dominación modulando distintas intensidades de violencia física y simbólica, articulando así los términos que rigen el contrato allí establecido:

Cuando él se sentó en la cama, impidió que yo lo hiciera y llevó sus manos a mi cuello, lo abarcó como si fuera a ahorcarme, me miró muy serio y cantó bajito para que sólo yo lo escuchara. Si Adelita se fuera con otro, la seguiría por tierra y por mar, si por mar en un buque de guerra, si por tierra en un tren militar. (63-64)

Del mismo modo, a través del acto sexual, esta vez abiertamente violento y no consensuado, se establece la pertenencia del otro en La sembradora de cuerpos. 
En el texto de Potdevin, Farfán luego de acceder al cuerpo de Frida por medio de la violación, le impone su ley de dominación simbólica, declara su cuerpo territorio de su pertenencia: "Desde ayer nadie te puede tocar; estás marcada" (Potdevin 58). Este caso, como se verá más adelante, tiene otra serie de aristas que complejizan esta afirmación como el restablecimiento del orden de dominación masculino. Después de esta declaración, en la que Frida tiene una agencia nula por la posición inerme en la que se encuentra respecto al potencial de violencia que puede desplegar Farfán, él la violenta sexualmente de manera reiterada e incluso la nombra unilateralmente "su mujer". En este escenario opera una violencia colonizadora, Farfán se declara colonizador y, por tanto, controlador, del territoriocuerpo de Frida, pues en el contexto de la disputa territorial en el que se desarrolla la novela, "el cuerpo inscrito como territorio y su afinidad con el biopoder es la forma última de control [...]" (Segato, La guerra 75).

Las situaciones descritas en las narraciones son críticas en la medida en que ilustran cómo en los escenarios del conflicto, recaen sobre las mujeres de manera sistemática, altos grados de violencia frente a la cual ellas no puede hacer resistencia, por las condiciones de vulnerabilidad económica, política y social que las constituyen en esos contextos determinados.

\section{Relaciones contractuales del cuerpo}

El cuerpo de la mujer está además expuesto a la violencia en el espaciofunción que le es ofrecido en el marco de la economía del capital. En los contextos sociales representados se evidencia, de manera recurrente, cómo las posibilidades relacionales socio-económicas de la mujer se restringen a "permitir" la explotación sexual de su cuerpo por un otro "masculino" heteropatriarcal. Esta lógica contractual expone el modo en que determinados roles de género tradicionales limitan y direccionan los procesos de subjetivación de las mujeres, obligándolas a aceptar la instrumentalización de su cuerpo, el cual, al ser consumido por el otro, es desterritorializado y expropiado para sí. En este sentido, el cuerpo es 
objetualizado en una doble vía, tanto por quien lo consume, como por quien lo "ofrece”, constituyéndose así una lógica sacrificial.

Las precarias condiciones de existencia de Adelita y su madre como damnificadas de la avalancha, condicionan las posibilidades de su desenvolvimiento social. Es por esto que Nacho, ese policía mayor, aparece como una posibilidad en la vida de Adelita a sus catorce años. Entre ellos se establece una lógica transaccional explicitada en que este le envía dinero a la madre de manera periódica; paga, en principio, el colegio de Adelita y le ofrece además una vida sin "trabajar". A cambio, lo que se le demanda a ella es la disposición exclusiva de su cuerpo en función de la satisfacción del deseo sexual de él y de otras demandas de afirmación de su masculinidad, "Nacho me observaba antes de acostarse, obligándome a desnudarme y a dar vueltas alrededor de la cama, en un juego que inventó para divertirse y pasar el tiempo mientras le daba sueño" (Peláez 100). En este "juego" en el que él se escondía en una especie de ático, al que ella no podía mirar, Adelita debía limpiar su uniforme policial, pulir sus botas hasta lastimar sus piernas donde las soportaba: "Sentía su mirada fija desde el techo y me daban ganas de llorar, quizá de rabia, pero no lloraba. Odiaba ese momento que me hacía sentir esclava del hombre grande que me dominaba, un gran señor de uniforme y manos recias al que añoraba cuando se iba de campaña" (100).

El ritual de violencia sexual impuesta continúa con un baile y termina con la obligación de masturbarse en la cama con una almohada mientras él mira desde lo alto, donde ella no puede verlo, solo puede escuchar lo que su voz ordena. El modo en que Adelita describe la escena expone metafóricamente el modo en que la dominación patriarcal se iguala a la ley divina, al ser representada como ese mandato omnipresente que regula y determina el accionar del cuerpo de la mujer. En esa legislación impuesta como sagrada en el orden social ella puede reconocerse sometida, sin embargo, no puede abstraerse de esa lógica de dominación que aliena su propio cuerpo.

El régimen contractual que demanda de la mujer la capitalización de su cuerpo aparece, al igual que en las relaciones de pareja, en todo tipo de relaciones 
sociales. Adelita, con su hija enferma, requiere ir a Bogotá para que esta sea tratada. En busca de ayuda para poder hacerlo recurre al Capitán Rojas, quien ofrece una libreta de direcciones de personas que la podrían ayudar en Bogotá. Las condiciones son claras, esta ayuda representa su sometimiento:

Cuando llegue a Bogotá, deberá llamarme. ¡Es una orden! -Me miró y sonrió, suavizando su expresión. Me recibirá cuando la visite, ¿verdad? Podremos terminar lo que no nos han dejado terminar... ¿Me entiende? cuando sonreía, se le veía algo torpe. -Bueno, sí... después que me hayan atendido a Angelita -dije, y extendí la mano. -No tenga afán, aún debe hacer algo por mí, Adelita. Es el momento de recompensar lo que haré por usted. ¡Sea amable! (54)

Una vez más esta escena evidencia otra de las violencias que recaen contra la mujer, la de la demanda constante de su corporalidad para el consumo sexual como mercancía de cambio, pues en el contexto capitalista patriarcal la mujer solo cuenta con su corporalidad para negociar los términos materiales de su propia existencia. Este estado de cosas, como lo expone Silvia Federici en su texto: Calibán y la bruja. Mujeres, cuerpo y acumulación originaria (2004), responde a un largo proceso de devaluación del trabajo de la mujer, operado desde los primeros siglos de la imposición del paradigma capitalista, que cuenta con algunos antecedentes, como la campaña de los artesanos europeos en contra del trabajo de la mujer (146).

La desvalorización social del trabajo de la mujer respondía, entre otras cosas, a la necesidad de articular una nueva distribución sexual del trabajo, en la que ella tenía asignada la reproducción de la vida en términos biológicos, es decir, la reproducción y el cuidado de la nueva fuerza de trabajo necesaria para el crecimiento del régimen del capital. En este sentido, con la emergencia de la familia como institución al servicio del capital, la mujer fue reducida socialmente de manera forzada a una labor familiar. En este proceso, de limitación de las 
posibilidades de las mujeres, comenzó a considerarse todo trabajo por ellas realizado como trabajo doméstico y por tanto no asalariado, de ahí su imposibilidad para la obtención de los medios de subsistencia, que la dirigieron de manera paulatina a la dependencia de una masculinidad asalariada. En palabras de Federici, esto fue lo que constituyó el "patriarcado del salario" (150).

Esta dinámica de la organización social impuesta por las lógicas del capital estructuró no solo esas relaciones de dependencia de las mujeres sobre los hombres, sino también las lógicas de la pertenencia, discutidas anteriormente respecto a las novelas, en las que el hombre concibe a la mujer como su propiedad:

De acuerdo con este nuevo «contrato sexual», para los trabajadores varones las proletarias se convirtieron en lo que sustituyó a las tierras que perdieron con los cercamientos, su medio de reproducción más básico y un bien comunal del que cualquiera podía apropiarse y usar según su voluntad [...]. Pero en la nueva organización del trabajo todas las mujeres (excepto las que habian sido privatizadas por los hombres burgueses) se convirtieron en bien común, pues una vez que las actividades de las mujeres fueron definidas como no-trabajo, el trabajo femenino se convirtió en un recurso natural, disponible para todos, no menos que el aire que respiramos o el agua que bebemos. (Federici 148)

\section{El mandato de la maternidad}

"El viejo ideal del deber-ser-de-la-mujer no
se bate fácilmente en retirada,
solapadamente regresa o vuelve a
reproducirse tomando nuevas formas: su
encarnación contemporánea agita los pies
entre pañales y chilla sin descanso junto a
nosotras". (Meruane 20)

En línea con estos planteamientos de Federici, la noción de familia moderna leída como una institución funcional al capital se articula a partir de la apropiación y expropiación violenta del cuerpo de la mujer. En este proceso de configuración 
biopolítica va a ser central el rol maternal-reproductivo al que queda supeditada la subjetividad y la corporalidad femenina. Esta subordinación se irá afianzando a lo largo de siglos de manera sistemática como un mecanismo más de la dominación patriarcal-estatal, al delimitar la maternidad como el horizonte vital de toda mujer.

Precisamente, en el marco de esta lógica se hacen comprensibles las resistencias y debates críticos que se han constituido en torno a las implicaciones de este régimen maternal $\mathrm{y}$, otros regímenes de dominación sobre la mujer, en distintos momentos de la historia. En este sentido, han sido fundamentales las discusiones que al respecto han desarrollado diferentes feminismos durante el siglo XX y lo que va corrido del XXI. Muchos de ellos han planteado tanto "la necesidad de desligarse de la función materna y de la famosa figura del "ángel del hogar" como destino inevitable de la mujer, consagrada por esta ideología a la crianza de los hijos" (Amaro 14), como la necesidad de resemantizar la significación de esta experiencia, en el marco de los procesos de empoderamiento de la mujer y de liberación de su cuerpo del yugo patriarcal, a partir del ejercicio de "desmantelar la idealización y la romantización de lo materno" (Amaro 15).

Específicamente, en las novelas de Peláez y Potdevin la representación de la maternidad está cargada de estas disputas significantes, las cuales se complejizan al performativizarse en las territorialidades del conflicto. En el contexto particular de estas narrativas, la maternidad opera como un factor limitante de las posibilidades de las mujeres representadas, al funcionar en los términos tradicionales como un mecanismo que sujeta, aún más a la mujer, a la dominación patriarcal y al intensificar su dependencia a la subjetividad masculina hegemónica. Este modo de estructuración del problema responde, en primer lugar, a los espacios específicos representados, sumamente precarios y vulnerables; en segundo lugar, a las subjetividades específicas que son atravesadas por la maternidad: niñasadolescentes; y, en tercer lugar, al modo en que este régimen se instaura en los cuerpos: la violación y la sexualidad abusiva.

El primer caso es el de Petrona. Su hijo Francisco fue producto de un acto de violación cometido contra ella por un grupo de guerrilleros con el que había 
comenzado a vincularse. Esta génesis del infante marca el modo en que él viene a encarnar múltiples modulaciones de la violencia: primero, desde el plano nominal, su nombre Francisco, fue puesto en memoria de su abuelo, quien desapareció a manos de grupos paramilitares cuando la familia de Petrona fue desplazada de Boyacá. Este sustantivo nominal se instituye no solo como un acto de memoria por el padre desaparecido, sino que también representa, simbólicamente, el movimiento cíclico de la violencia, que hace que esta recaiga una y otra vez de manera sistemática sobre determinadas subjetividades precarias:

Una vez se me ocurrió que cuando uno no tiene nada en la vida, la vida se abre camino hacia la más nada. En nuestra finca en Boyacá, cuando empezaron a llegar los paras, Mami nos dijo que no viéramos nada, que no oyéramos nada. Si le hacíamos caso, saldríamos de ahí con vida. Nos volvimos sordos y mudos, pero aún así perdimos. La historia se repitió, y perdimos otra vez. No teníamos otra opción. (Rojas 391)

Segundo, la corporalidad del niño constituye la materialización de una de las violencias más recurrentes contra el cuerpo de la mujer, la de la violación. En ese sentido, Francisco, como significante de determinado tipo de violencia es una memoria corporalizada, que como toda memoria es necesariamente conflictiva, "cuando estaba sola, o solo con Francisco, me sentía en paz. Otras veces veía en Francisco rasgos que no eran míos y que pertenecían a aquella terrible noche" (391). Tercero, la aparición del niño-hijo cristaliza el estatus de dependencia de la mujer frente al hombre, lo cual se evidencia en el hecho de que su presencia es la que conforma el núcleo filial. Petrona señala al respecto que ella necesitaba un padre para su hijo (390), de ahí que establezca con Gorrión una familia, que aquí, una vez más, pese a la agencia de Petrona en la capitalización de la culpa de Gorrión, es símbolo del sometimiento y abnegación a la que la mujer se ve obligada. En esta narrativa, ella debe aceptar vincularse con una persona que fue "cómplice" 
de su propia violación performativizando literalmente una desmemoria respecto a lo ocurrido.

El caso de Adelita no es menos complejo. Cuando Nacho es asesinado, ella se encuentra en embarazo, así, su hija Angelita nace huérfana, en el mismo vacío paternal que tuvo la misma Adelita. Con el regreso de esta a la casa de su madre, después de este asesinato, la niña que sufre una enfermedad crónica es prácticamente entregada a su abuela, para que ella sea quien la cuide. La manera en que se desarrolla el relato va mostrando cómo en Adelita no se da un proceso de identificación con el modelo materno, ella no se reconoce a sí misma como madre.

En este orden, la relación de Adelita con la niña es distante y angustiosa, ella señala que la tuvo poco en sus brazos, al respecto dice: "me causaba temor abrazarla al verla tan pequeñita, y escucharla llorar me desesperaba porque no entendía cómo siendo tan niña podía sufrir tanto" (Peláez 27). Angelita y su enfermedad son la proyección de la culpa, por no haberla querido tener, y de los estados emocionales que Adelita había padecido durante su vida, "yo creo que de los sustos que pasé, Angelita nació enferma" (27). De este modo, ella viene a encarnar el trauma y la culpa, y es esto lo que articula las mediaciones entre madre e hija.

Asimismo, la niña representa el obstáculo que le impide a Adelita recobrar la infancia perdida, esa infancia que fue violentada por la irrupción de la masculinidad heteropatriarcal de Nacho. El regreso a casa, a la misma habitación de su niñez, que no había cambiado nada desde su partida, implica para ella la posibilidad de reactualizar la infancia que no ha dejado de definir su subjetividad, lo que se ejemplifica en el hecho de que todo el tiempo lo que le va aconteciendo se estructure psíquicamente con canciones infantiles. En ese proceso nostálgico de evocar desde su habitación ella recuerda, "las tardes en Armero y los juegos con los niños de la cuadra" (31), hasta que los juegos fueron cambiando y:

Cucú, cucú, cantaba la rana. Cucú, cucú, debajo del agua. Cucú, cucú, pasó un caballero. Cucú, cucú, con capa y sombrero. Cucú, cucú, pasó 
una señora, cucú, cucú, con traje de cola. Cucú cucú y pasó mi caballero con traje de policía y ahí, creo, terminó mi infancia. Una corta infancia de la que sólo recuerdo los juegos. (35-36)

Sus procesos de subjetivación infantil son trastocados por la aparición de Nacho y los repertorios de violencias que vienen asociadas a él. Del mismo modo, en ese presente evocador, Angelita, como una extensión de él y de su vida conyugal, emerge como actualización de esa fractura y de una estructura de dominación que demanda de ella unas actuaciones, que ella angustiosamente desde la inacción, se resiste a asumir.

La negación se instaura entonces como la forma en que Adelita establece un vínculo con su hija, a través de un doble registro de la negatividad: el de negarse a alimentarla, metáfora de lazo afectivo, y el de no reconocerse como madre que, en último término, es la negación del reconocimiento de la hija. Esta negatividad relacional retorna de modo especular desde la niña y su oposición a recibir el alimento dado por otras mujeres, además de su no identificación de la madre: "Los quejidos de Angelita se escuchaban débiles, desde hacía unos días tenía su cuna junto a la cama de mamá, ya poco la atendía yo. Me daba pena que no tomara su tetero, verla tan flaquita. Cuando la cargaba, era como un atadito de plumas y creo que ni me conocía" (153).

En esta relación opera un proceso de desarticulación identitaria que hace comprensible que, finalmente, sea la muerte de la niña y su conversión en "amuleto", que funciona como huella experiencial, la que instaure el régimen de liberación de Adelita. Lo que muere con Nacho y Angelita es la dominación del mandato patriarcal, representada por el primero como estructura conyugal y por la segunda, como estructura maternal. Libre de estas dos articulaciones impuestas como mandato ella puede afirmar su propia subjetividad y agenciarse de otro modo en el contexto opresor. Así, hacia el final de la novela ella comienza a decidir qué tipo de vínculos contractuales establece social y afectivamente, a partir de la emergencia de su propia voluntad. 


\section{Restablecer un orden, el mandato inscrito en el cuerpo otro}

La violación es la principal violencia sexual que se ejerce contra las mujeres en el marco de estas narrativas del conflicto. Esta se entiende aquí en el sentido en que es definida por Rita Segato en su importante contribución respecto al tema, "La estructura de género y el mandato de violación", donde la define como "el uso y abuso del cuerpo del otro, sin que éste participe con intención o voluntad comparables" (22). En el caso específico de estas narrativas ese uso y abuso se ejerce sexualmente sobre el cuerpo la mujer. Como se mencionó antes, Petrona fue violada por un grupo de jóvenes guerrilleros que ejercían el control territorial en Los Cerros y Frida fue violada, de manera reiterada, por Farfán el líder del grupo paramilitar que desplazó a toda la población de Las Brisas.

En el trabajo referido de Segato, basándose en el análisis de los testimonios de presos condenados por violación en la ciudad de Brasilia, la autora analiza el modo en que la violación opera como un ejercicio de poder que busca sostener y reproducir el ordenamiento estructural jerarquizado del género. En este sentido, esta forma de violencia se articula como un mandato que debe ser ejercido para mantener las estructuras de poder:

La idea de mandato hace referencia aquí al imperativo y a la condición necesaria para la reproducción del género como estructura de relaciones entre posiciones marcadas por un diferencial jerárquico e instancia paradigmática de todos los otros órdenes de estatus -racial, de clase, entre naciones o regiones. Esto quiere decir que la violación, como exacción forzada y naturalizada de un tributo sexual, juega un papel necesario en la reproducción de la economía simbólica del poder cuya marca es el género [...]. Se trata de un acto necesario en los ciclos regulares de restauración de ese poder. (Estructuras 13) 
Con esta argumentación, Segato se opone a los discursos que normalizan la violación al tipificarla como una práctica irracional, no instrumental, que no posee un fin ulterior; por el contrario, ella explicita la lógica sistémica que la configura en el marco de un orden social, en el que funciona como un mecanismo con una teleología definida:

De tal modo, la violación puede comprenderse como una forma de restaurar el estatus masculino dañado, aflorando aquí la sospecha de una afrenta y la ganancia (fácil) en un desafío a los otros hombres y a la mujer que cortó los lazos de dependencia del orden del estatus, todos ellos genéricamente entendidos. En rigor de verdad, no se trata de que el hombre puede violar, sino de una inversión de esta hipótesis: debe violar, si no por las vías del hecho, sí al menos de manera alegórica, metafórica o en la fantasía. (Estructuras 37-38)

Esta función restaurativa de orden patriarcal es evidente en el caso de las reiteradas violaciones que sufre Frida por parte de Farfán en la novela de Peláez. Desde la primera incursión de los paramilitares al pueblo esta joven-niña de doce años desafía la dominación de este grupo armado a partir de la confrontación con su líder, Farfán. La gente del pueblo está formada por orden de los paramilitares en la cancha, de ahí los violentos van retirando a algunas personas que son llevadas con ellos y desaparecidas. Cuando este hombre se acerca, ella se niega a decirle su nombre y lo increpa, señalando que él antes había estado ahí con una brigada de salud del Ejército, que a su maestra la mató un grupo guerrillero liderado por un hombre que se parece a él, y finalmente con la pregunta por la responsabilidad por los muertos que trae el río. Cada cuestionamiento de Frida es una denuncia, así su primer comentario expone la connivencia de las Fuerzas Militares y los grupos paramilitares; la segunda, visibiliza la indistinción entre los actores armados, cuyo accionar simplemente violenta a la población, más allá de los argumentos discursivos que sustentan sus prácticas; y tercero, la pregunta final, modula un 
reclamo por la responsabilidad, y por tanto es un reclamo de justicia, ante los brutales asesinatos que se materializan cada día en el río cuando bajan cuerpos desmembrados, dice ella, "claro, como saben que los muertos no pueden vengar la injusticia. -Alza la voz más" (Potdevin 45).

En esta escena Frida se apropia del lugar de la enunciación, cada cosa que dice desplaza, por un instante, el lugar de la dominación. Así, Farfán queda articulando un performance dudoso y sometido, su mentón tiembla y solo atina a apegarse a su libreto violento, como espacio seguro, para recuperar ese lugar de la enunciación perdido. Después de terminar la ronda por cada familia parada en la cancha, decreta: "Tienen plazo hasta mañana a las diez para recoger sus cosas y marcharse. [...] -No los queremos ver aquí" (45).

Lo descrito en este apartado es solo la primera afrenta de Frida al poder patriarcal de la violencia. Al día siguiente, cuando toda la gente del pueblo parte, ella se niega a irse y se esconde aún de su propia madre, para permanecer en el pueblo, cumpliendo desde su individualidad la afirmación que como colectivo ella había enunciado en la tarde anterior: "No vamos a irnos", “¡Nacimos aquí, somos de aquí!" (46). En el gesto de la afirmación de su pertenencia al territorio, Frida desafía de manera directa la soberanía masculina de los violentos que, por la fuerza y el derecho natural dado en la sociedad patriarcal, son los dueños de los cuerpos y los territorios. Ella impone entonces su presencia corporal como desacato y como reclamo sobre el territorio que, existencial y sensiblemente, le pertenece. En este contexto de disputa por la hegemonía, ocurre el acto de su violación, como una forma de restablecimiento del orden jerárquico natural:

El hombre da dos zancadas y la agarra del brazo con violencia. La empuja al rancho más cercano y la tira al piso. Frida vuelve al miedo. Siente el estómago descompuesto. Enmudece. Tiene el vestido de mariposas que usa desde hace dos días. En el piso, el vestido se encarama por encima de los muslos oscuros y los inocentes pudores. Farfán desabrocha su cinturón. Se tumba sobre Frida. Ella patalea y grita, araña la cara de Farfán. El olor 
fresco del hombre la asquea. Él la inmoviliza con su peso, le aprieta el cuello con la mano sudorosa y ordena se quede quieta; ella cierra los ojos, muerde con fuerza su lengua. Oye el repiquetear de un pájaro carpintero en un palo de guásimo. Farfán termina y se marcha. (55)

En el despliegue de este acto violento el perpetrador cumple su función como moralizador, como castigador ante el desacato a una estructura de poder, de la cual él es garante. Aquí, Josefo Farfán articula ese lenguaje performativo de la masculinidad, que es el "lenguaje violento de conquista y preservación activa de un valor" (Segato, Estructuras 38). De este modo, la violación se inscribe como un "movimiento de restauración de un estatus siempre a punto de perderse e instaurado, a su vez, a expensas y en desmedro de otro, femenino, de cuya subordinación se vuelve dependiente" (38). La violación de Frida es la afirmación y reafirmación última del dominio masculino sobre el territorio-cuerpo ${ }^{7}$, pues su accionar, como afirmación de la propia soberanía sobre su cuerpo-territorio, constituía una negación de este. En este sentido, su modulación agencial articulaba una amenaza al estatus mismo de la dominación y, por tanto, según los acuerdos de género patriarcales, su desafío debía ser inmediatamente castigado.

Por otra parte, el acto de la violación de Petrona se circunscribe a esta misma lógica estructural. Su agravio al régimen patriarcal, esta vez, lo constituye su negación a continuar participando activamente en uno de los repertorios económicos de la violencia del conflicto, el del secuestro. En un principio ella colabora activamente con la guerrilla para el secuestro de Chula y su hermana, pero durante el "operativo", Petrona desiste y opta por ayudar a Chula a retornar a su casa. Posterior a esta acción es ella, quien secuestrada por los guerrilleros, es violada hasta que la dejan agonizante en un terreno baldío.

7 En "Cambio del paradigma territorial" Segato señala que existe un nuevo régimen de la territorialidad en el que el cuerpo "pasa a constituir, en sí mismo, terreno-territorio de la propia acción bélica" (Segato, La guerra 75). Así, "los cuerpos y su ambiente espacial inmediato constituyen tanto el campo de batalla de los poderes en conflicto, como el bastidor donde se cuelgan y exhiben las señas de su anexión" (75). 
En este caso, la violación de Petrona es la consecuencia por fallarle al régimen patriarcal de la guerra. Esto es lo que expresa Ramoncito tras la muerte de un amigo suyo, justo antes de enlistarse en la guerrilla, cuando Petrona le advierte que debe alejarse de esos grupos armados, él responde que su corazón de mujer de nada le sirve a él (Rojas 64). La guerra inscribe a los sujetos necesariamente en el régimen sensible de la desafección, para que así estos puedan ser funcionales a sus dinámicas. En este orden, Petrona y su abstraerse en medio de la acción violenta denota un proceso de afectación, que contradice esas lógicas anestésicas de la guerra y, por lo tanto, ella debe ser sancionada. Su duda tensiona un orden, pues su acción introduce un juicio valórico que pone en cuestión el proceso de deshumanización del otro, de esos "ricos" o clases altas que son simplemente el enemigo.

Sobre Petrona se ejerce entonces la violación colectiva como condena, "esto es lo que le hacemos a los traidores" (326), dice uno de los agresores. Se trata de un acto disciplinador que se imprime en el cuerpo de ella, pero que dialoga con todas las subjetividades que constituyen el grupo, no solo las presentes. La violación, desde su dimensión intersubjetiva, es un enunciado que se manifiesta "como un acto expresivo revelador de significados" (Segato, Estructuras 35). Esta enunciación violenta inscripta en el cuerpo de la mujer, en este caso, es reforzada de manera explícita a través del significante de poner la ropa interior de la joven sobre sus pantalones y llenarla de tierra, esto funciona como signo inequívoco del trastocamiento violento de su sexualidad y del carácter ejemplificador de esta violencia.

Este impacto de la violencia que se ejerce contra Petrona, primero drogándola y luego violándola, termina generando en ella un doble proceso de desposesión: corporal y subjetiva, "[Y]o era una mujer sin nombre tirada en un lote baldío [...]. Estaba completamente inmóvil, quieta como un ratón. Era una mujer sin cuerpo. Quizá mi cuerpo tenía frío. No lo supe porque el cuerpo no me temblaba" (Rojas 352). Este proceso de des-subjetivación también resulta evidente en el modo impersonal en que la misma Petrona narra, en tercera persona, cómo 
fue encontrada esa noche por Doña Fausta, quien halló su cuerpo en el pasto: “era un cuerpo golpeado, un cuerpo muerto. Habían apaleado a la chica y traía su ropa interior llena de tierra y se la habían puesto encima del pantalón" (387). Ella paulatinamente va recuperando su subjetividad, su memoria, "con el tiempo, la diferencia entre un recuerdo y un sueño se esclareció. Recordé las cosas que se suponía no debía recordar" (390). Sin embargo, esta memoria no le permite agenciarse frente a la violencia padecida, debido a que la imposición violenta sobre su cuerpo la ha dejado a merced de otra narrativa que, en sus condiciones específicas, la somete firmemente al yugo patriarcal, esta es la de la maternidad, que viene a recalcar la cíclica fatalidad inscripta en determinados cuerpos.

\section{A modo de conclusión}

Las novelas analizadas revelan la amplitud y multiplicidad de las prácticas violentas que se inscriben en los cuerpos de las mujeres en unos contextos del conflicto determinados, en los que las condiciones de precariedad y vulnerabilidad social intensifican y multiplican el impacto de estas violencias. En estas territorialidades representadas, los repertorios de violencia ejercidos contra las mujeres responden a las lógicas estructurales de la dominación patriarcal que son, a su vez, las lógicas de la guerra y del capital. Esta estructura del poder se manifiesta en los procesos de socialización y racionalización cotidianos. Así, sus violencias que están sedimentadas en el marco social y, por tanto, normalizadas, se articulan sistemática y performáticamente como formas de afirmación y legitimación masculina, en detrimento de las subjetividades femeninas.

En este contexto se instauran los regímenes de violencia expuestos: pedofílicos, de apropiación y pertenencia de los cuerpos; además de los contractuales y maternales. Todos ellos limitan y determinan unas condiciones de posibilidad para el desenvolvimiento social y vital de la mujer. Del mismo modo hacen presencia otras violencias como la violación, que se impone en el cuerpo de la mujer como mandato, el cual es ejercido por un otro como un mecanismo de 
restauración del orden masculino patriarcal que, como estatus conquistado, debe ser de manera constante reafirmado.

En estas representaciones emergen también posibilidades de resistencia frente a estas violencias a través de la puesta en escena de lógicas afectivas, que se niegan a la reproducción de la violencia (Régimen Antigónico) y que establecen vínculos de solidaridad que tienden a la reconfiguración del lazo social. Asimismo, aparecen subjetividades femeninas que, afirmando su pertenencia al territorio, se imponen y demandan justicia.

En este sentido, estas problematizaciones desde el plano de la representación logran exponer las formas en que operan estos distintos regímenes, extendiendo una mirada complejizadora sobre ellos que los desnaturaliza, explicitando así las estructuras de dominación y complicidad social que las sostienen, pero además los agenciamientos que los inhabilitan.

\section{Bibliografía}

Amaro, Lorena. "Maternidades "líquidas": feminismos y narrativas recientes en Chile". Revista Chilena de Literatura 101 (2020):13-39.

"Atención y reparación para las mujeres víctimas de violencia sexual". Unidad para la Atención y la Reparación Integral a las Víctimas (2020). https://www.unidadvictimas.gov.co/es/enfoques-diferenciales/atenciony-reparacion-para-las-mujeres-victimas-de-violencia-sexual/57070. 5 de octubre de 2020.

Benjamin, Jessica. Los lazos del amor. Psicoanálisis, feminismo y el problema de la dominación. Buenos Aires: Editorial Paidós, 1996.

Bourdieu, Pierre. La dominación masculina. Barcelona: Editorial Anagrama, 2000.

Butler, Judith. Cuerpos que importan. Sobre los límites materiales y discursivos del sexo. Buenos Aires: Editorial Paidós, 2002.

Centro Nacional de Memoria Histórica. Género y memoria histórica, Balance de la contribución del CNMH al esclarecimiento histórico. Bogotá: CNMH, 2018. 
. La guerra inscrita en el cuerpo. Informe nacional de violencia sexual en el conflicto armado. Bogotá: CNMH, 2017.

. La masacre de Bahía Portete. Mujeres wayúu en la mira. Bogotá: CNRR-GMH, 2010.

. Mujeres y guerra. Victimas y resistentes en el Caribe colombiano.

Bogotá: Taurus, 2011.

. ¿Qué papel jugó el tema de género en el conflicto?”. Centro Nacional de Memoria Histórica.

http://www.centrodememoriahistorica.gov.co/micrositios/balancesjep/genero.html. 5 de octubre 2020.

Corporación Sisma Mujer. Colombia: Mujeres, Violencia Sexual en el Conflicto y el Proceso de Paz. 2013.

. "Reconocer y erradicar la violencia sexual contra las mujeres para consolidar una paz estable y duradera". Boletín Corporación Sisma Mujer 17 (2019): 1-19.

Esquivel, Gloria Susana. Animales del fin del mundo. Bogotá: Alfaguara, 2017.

Escobar, Melba. La mujer que hablaba sola. Bogotá: Planeta, 2019.

Federici, Silvia. Calibán y la bruja. Mujeres, cuerpo y acumulación originaria. Madrid: Traficantes de sueños, 2010.

Ferreira, Daniel. La rebelión de los oficios inútiles. Buenos Aires: Alfaguara, 2014.

Gargallo, Francesca. Feminismos desde Abya Yala. Ideas y proposiciones de las mujeres de 607 pueblos en nuestra América. Ciudad de México: Editorial Corte y Confección, 2014.

Gaviria, Víctor. La vendedora de rosas. Colombia: Producciones Filmamento, 1998.

Llanos, Bernardita. "Esas locas madres de Pedro Lemebel". Desdén al infortunio.

Sujeto, comunicación y público en la narrativa de Pedro Lemebel. Fernando

Blanco y Juan Poblete, editores. Santiago: Editorial cuarto propio, 2010. 181-209.

Luongo, Gilda. “¿La ciudad de las mujeres? Una ética-política en tus crónicas, Pedro

Lemebel". La vida imitada: Narrativa, performance y visualidad en Pedro Lemebel. Fernando Blanco, editor. Madrid: Iberoamericana Vervuert, 2020. 155-176.

Meruane, Lina. Contra los hijos. Santiago: Random House Mondadori, 2018. Ospina Pizano, María. Azares del cuerpo. Bogotá: Laguna Libros, 2019.

Peláez, Gloria. Era mucho el miedo. Bogotá: Ediciones desde abajo, 2016.

Potdevin, Philip. La sembradora de cuerpos. Bogotá: Planeta, 2019.

Rojas, Ingrid. La fruta del borrachero. Nueva York: Vintage Español, 2018.

Segato, Rita Laura. Las estructuras elementales de la violencia: ensayos sobre género entre la antropología, el psicoanálisis y los derechos humanos. Buenos Aires: Universidad Nacional de Quilmes, 2003. . La guerra contra las mujeres. Buenos Aires: Prometeo libros, 2018.

Sófocles. Tragedias. Madrid: Editorial Gredos, 1981. 
CATEDRAL TomAda: Revista de crítica literaria latinoamericana / Journal of Latin American Literary Criticism Articulaciones de la violencia contra la mujer en el marco de las narrativas del conflicto armado colombiano

Tarquino, Pilar. Voces desde el desvelo. Colombia: Editorial Atenea, 2017.

Valencia, Sayak. Capitalismo gore. España: Editorial Melusina, 2010.

Vélez, Pilar. El expreso del sol. Miami: Snow Fountain Press, 2015.

(cc) EY New articles in this journal are licensed under a Creative Commons Attribution 4.0 United States License.

ULLS D-Senfe This site is published by the University Library System, University of Pittsburgh as part of its D-Scribe Digital Publishing Program and is cosponsored by the University of Pittsburgh Press. 